www.jmscr.igmpublication.org

Impact Factor (SJIF): 6.379

Index Copernicus Value: 79.54

ISSN (e)-2347-176x ISSN (p) 2455-0450

crossrefDOI: https://dx.doi.org/10.18535/jmscr/v6i8.130

Journal Of Medical Science And Clinical Research

\title{
A Cross-sectional Study to Assess the Relation between Physical Fitness Index and Body Mass Index in Medical Students of Index Medical College, Indore
}

\author{
Authors \\ Dr Aveninder Meet Nayyar", Dr Prashant Sharma ${ }^{2 *}$, Dr Manila Jain ${ }^{3}$ \\ ${ }^{1,2}$ Assistant. Professor, ${ }^{3}$ Professor \\ ${ }^{1,3}$ Dept. of Physiology, Index Medical College, Hospital and Research Centre, Indore \\ ${ }^{2}$ Dept. of Physiology, Amaltas Institute of Medical Sciences, Dewas \\ *Corresponding Author \\ Dr Prashant Sharma
}

\begin{abstract}
Introduction: The present study was carried out in Index Medical College \& Hospital, Indore with the objective of assessing the physical fitness of medical students and to study relation between BMI and physical fitness so that suitable corrections can be made to minimize the rate of morbidity.

All the students satisfying the inclusion criteria and willing were included in the study. Two hundred students participated in study of which 82 were females and 118 were males.

Material \& Method: Queen's College Step Test was used to assess the physical fitness index. This is validated method for Indian subjects because of its simplicity and does not require skills. It classifies the subjects into four groups of physical fitness based on scores obtained. Heart rate recovery after exercise using QCT was used to calculate the scores. Results were analyzed using chi-square and ' $t$ ' test. Correlation was calculated using Pearson's coefficient of correlation ' $r$ '.

Conclusion: Females were in better state and physically more fit as they are calorie conscious and pursued some sort of physical activity.

Regular physical activity is important determinant of physical fitness.

PFI showed negative correlation with pulse rate and BMI and positive with physical activity.

Over weight and obesity reduce physical fitness significantly.

Study Design: Cross-sectional Study

Keywords: Physical Fitness Index (PFI) \& Body Mass Index (BMI).
\end{abstract}

\section{Introduction}

Physical fitness is defined as a set of attributes that people have or achieve that relate to the ability to perform physical activity. Physical fitness can be thought of as an integrated measure of most of the body functions (skeletomuscular, cardiorespiratory, haematocirculatory, psychone- urological and endocrine-metabolic) involved in the performance of daily physical activity with vigour and alertness, without undue fatigue and ample energy to engage in leisure time and meet above average physical stress encountered in emergency situation ${ }^{1}$. 
Most types of stress require varying degree of anatomical, physiological and psychological fitness. Anatomical fitness implies possession of all parts and organs of body which are essential for the performance of the task. Physiological fitness implies the capacity for the skilful performance and rapid recovery. Psychological fitness for a task implies that subject possess necessary emotional stability, drive or motivation, intelligence and skill. The fit man carries on a given grade of moderate work with less displacement of his physiological equilibrium ${ }^{2}$.

He can establish steady states of higher grades of work.

Lack of fitness has increased the rate of mortality and morbidity in today's life. Sedentary lifestyle, lack of physical activity, increasing stress due to increased commercialization, unhealthy food habits and inadequate sleep has reduced fitness to remarkable degree.

This has increased the risk of cardiovascular disorder and hence mortality and morbidity. Obesity has added to this risk many fold. There is substantial evidence that childhood and teenage obesity lays metabolic ground work for cardiovascular diseases in later life.

Fitness is strongly associated with BMI which is simple index of weight for height i.e. commonly used to classify individual into underweight, normal weight, overweight and obesity categories in adults. Even WHO has been using BMI as standard for recording obesity statistics since 1980. It is defined as person's weight in $\mathrm{kg} / \mathrm{ht}$ in $\mathrm{m}^{2}$. A person is categorized into normal $\mathrm{wt}$ if his/her BMI is between $18.5-24.99 \mathrm{~kg} / \mathrm{m}^{2}$, less than $18.5 \mathrm{Kg} / \mathrm{m}^{2}$ is underweight, between 18.5 $29.99 \mathrm{Kg} / \mathrm{m}^{2}$ is overweight and above $30 \mathrm{Kg} / \mathrm{m}^{2}$ is obese.

Mild deviation from normal range generally have minimal effect on fitness but larger deviation result in significant deterioration.

Regular physical exercise and little change in life style can keep a check on weight and improve efficiency of cardio-respiratory fitness to a significant level.

\section{Materials \& Methods}

The present study entitled "A Cross-sectional Study to Assess the Relation between Physical Fitness Index and Body Mass Index in Medical Students of Index Medical College, Indore" has been carried out in the Department of Physiology, Index Medical College and Hospital, Indore on Medical Students of Index Medical College and Hospital, Indore from January 2015 to July 2015.

Place of Study: Department of Physiology, Index Medical College and Hospital, Indore.

Study Design: Prospective, non-randomized, cross-sectional and observational study.

Study Period: From July 2015 to December 2015.

Study Population: All the medical students of Index Medical College \& Hospital, Indore formed the study population.

\section{Sample Size and Sampling Technique}

Of all the medical students studying in Index Medical College \& Hospital, Indore, 200 students of which 118 males and 82 females were selected for the study.

Sample size calculated by using formula $4 \mathrm{pq} / \mathrm{E}^{2}$ $(4 \times 0.5 \times 0.95 / 0.1 \times 0.1=190)$

Where; $p=$ prevalence; $q=$ absence $; E=$ error

Based on the prevalence formula for calculation of sample, 190 subjects were required, hence, we had included 200 subjects in the present study, justifying our sample size.

Convenient sampling technique was used for the present study.

\section{Inclusion Criteria}

- Medical student in the age group 18 to 30 years

- Healthy Medical Student of Index Medical College \& Hospital, Indore

- Medical student with known history of alcohol consumption and smoking reading at Index Medical College \& Hospital, Indore

- Student willing to provide his/her voluntary consent for participation in the present study 


\section{Exclusion Criteria}

- Student with locomotor and musculoskeletal disability

- History of cardiovascular disorders

- History of diabetes mellitus, hypertension and bronchial asthma

- History of major surgery in recent past

- Student on regular medication for any systemic disease

- Student undergoing physical conditioning programme

- Student not willing to provide his/her voluntary consent for participation in the present study

\section{Materials}

\section{Instruments}

1. Queen's College Step Test (16.25 inches bench)

2. Stop watch - to record the timing in seconds during the procedure

3. Multipara monitors - for recording:
a) Blood pressure
b) Heart rate
c) Oxygen saturation

4. Stethoscope

5. Weighing machine

6. Height scale

\section{Method for Data Collection}

All the exercise data was collected during morning hours between 08:00 am to 09:30 am to avoid any possible diurnal variation effects. Subjects were told to report half an hour before exercise.

The details of procedure was explained to subjects and demonstrated to allay any apprehension. They were asked to refrain from eating or drinking at least an hour before exercise and allowed to take rest for half-an-hour before exercise.

Before the test, anthropometric and physiological parameters were recorded. All the data was entered in the proforma of each subject.
Recording of physical anthropometry

Following parameters were recorded:

- Height was measured with subject (in centimeter) standing without shoes, nearest to $0-1 \mathrm{~cm}$

- Weight was measures in $\mathrm{kg}$ on a standardized machine nearest to $0.1 \mathrm{~kg}$

- Body mass index (BMI) was calculated for each subject from their height and weight using the formula BMI $=\mathrm{kg} / \mathrm{m}^{2}$

\section{Recording of physiological parameters}

In each subject following parameters were recorded in pre and post exercise period.

Pre-exercise recording was done in supine position after making them sit for 10 minutes.

1. Pulse rate

2. Systolic blood pressure

3. Diastolic blood pressure

4. Mean blood pressure

5. Respiratory rate

6. Oxygen saturation

7. Temperature

Multipara monitor was used for recording the variables.

Recording of same parameters was made in postexercise period.

Table No. 1 Mean BMI According to PFI Grading in Gender

$(\mathrm{N}=200)$

\begin{tabular}{|l|c|c|c|c|}
\hline $\begin{array}{l}\text { PFI } \\
\text { Grading }\end{array}$ & $\begin{array}{c}\text { Female } \\
\text { (Mean } \pm \\
\text { SD) }\end{array}$ & $\begin{array}{c}\text { Male } \\
\text { (Mean } \pm \\
\text { SD) }\end{array}$ & 't' value & P value \\
\hline Excellent & $21.75 \pm$ & $21.04 \pm$ & 0.705, & 0.485, \\
& $1.99(30)$ & $0.07(4)$ & $\mathrm{df}=32$ & $\mathrm{NS}$ \\
\hline Good & $24.98 \pm$ & $24.38 \pm$ & 0.520, & 0.605, \\
& $4.16(30)$ & $2.69(16)$ & $\mathrm{df}=44$ & $\mathrm{NS}$ \\
\hline Fair & $25.20 \pm$ & $28.78 \pm$ & -0.598, & 0.553, \\
& $1.38(8)$ & $16.80(43)$ & $\mathrm{df}=49$ & $\mathrm{NS}$ \\
\hline Poor & $32.93 \pm$ & $28.79 \pm$ & 2.495, & $0.015^{*}$ \\
& $4.04(14)$ & $5.83(55)$ & $\mathrm{df}=67$ & \\
\hline
\end{tabular}

Unpaired ' $t$ ' ' test applied. $P$ value $<0.05$, was taken as statistically significant

The above table shows the mean BMI according to $\mathrm{PFI}$ grading according to gender.

In the females, mean BMI was $21.75 \pm 1.99$ with excellent PFI grading, $24.98 \pm 4.16$ with good PFI 
grading, $25.20 \pm 1.38$ with fair PFI grading and $32.93 \pm 4.04$ with poor PFI grading.

In the males, mean BMI was $21.04 \pm 0.07$ with excellent PFI grading, $24.38 \pm 2.69$ with good PFI grading, $28.78 \pm 16.80$ with fair PFI grading and $28.79 \pm 5.83$ with poor PFI grading.

The mean BMI comparison between females and males for each PFI grading was done using unpaired ' $t$ ' test. In the excellent, good and fair PFI grading groups, there was no statistically significant difference between females and males $(\mathrm{P}>$ 0.05), showing comparable mean BMI. While in the poor PFI grading, there was a statistically significant difference between females and male with a higher BMI in females in comparison to the males $(\mathrm{P}<0.05)$.

Fig 01: Mean BMI According to PFI Grading in Both Genders

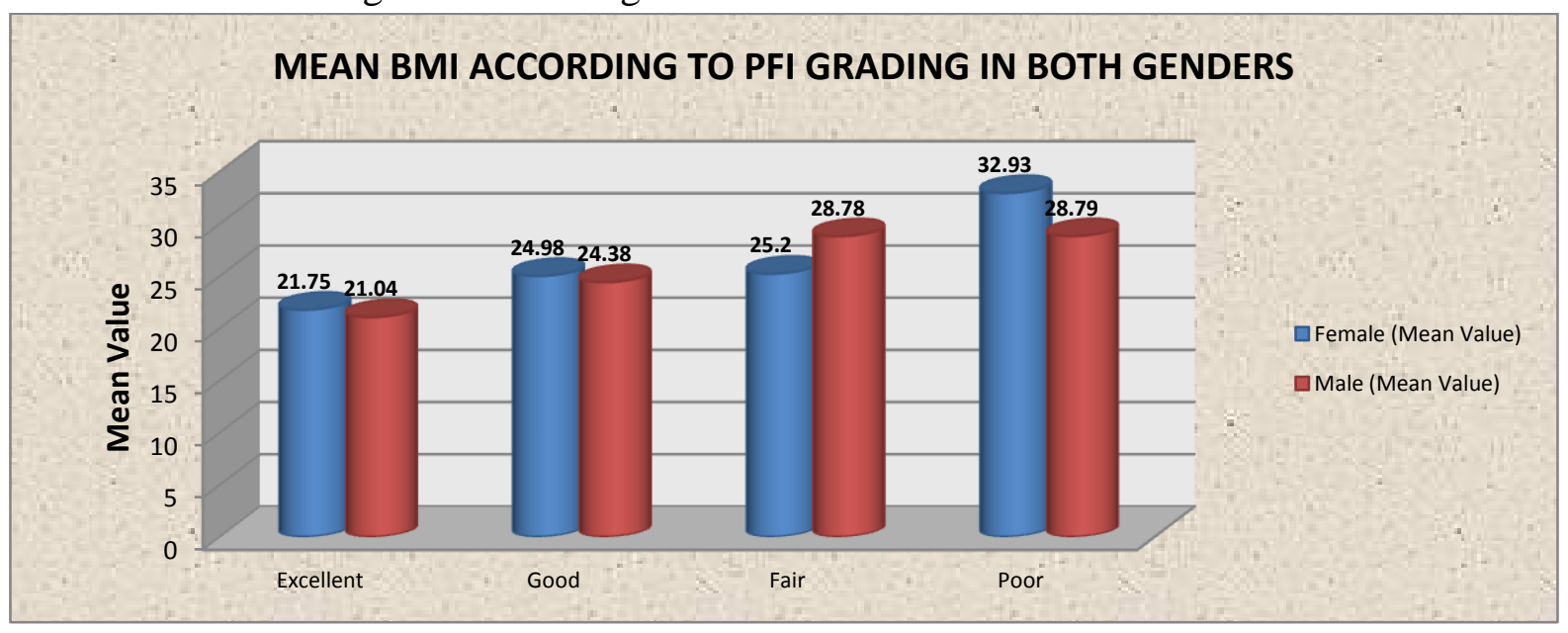

Table No. 2 Association of smoking with PFI grading

$(\mathrm{N}=200)$

\begin{tabular}{|l|c|c|c|c|c|c|}
\hline \multirow{2}{*}{$\begin{array}{l}\text { PFI } \\
\text { Grading }\end{array}$} & \multicolumn{2}{|c|}{ Absent } & \multicolumn{2}{c|}{ Present } & \multicolumn{2}{|c|}{ Total } \\
\cline { 2 - 7 } & No. & $\mathbf{\%}$ & No. & \% & No. & \% \\
\hline Excellent & 34 & 22.7 & 0 & 0.0 & 34 & 17.0 \\
\hline Good & 43 & 28.7 & 3 & 6.0 & 46 & 23.0 \\
\hline Fair & 34 & 22.7 & 17 & 34.0 & 51 & 25.5 \\
\hline Poor & 39 & 26.0 & 30 & 60.0 & 69 & 34.5 \\
\hline Total & 150 & 100.0 & 50 & 100.0 & 200 & 100.0 \\
\hline
\end{tabular}

Chi-square value $=34.16 \mathrm{df}=3, \quad \mathrm{P}$ value $=0.0001$, Significant

The above table shows the distribution according to presence or absence of smoking in relation to PFI grading.

There were 34 (17.0\%) subjects who had excellent PFI grading, 46 (23\%) had good PFI grading, 51

(25.5\%) had fair PFI grading and 69 (34.5\%) had poor PFI grading.

Majority of the subjects who did not smoke had an excellent PFI grading $34(22.7 \%)$ in relation to none in subjects who smoked. In 43 (28.7\%) subjects who did not smoke had good PFI grading in comparison to only $3(6.0 \%)$ subjects who smoked. 34 (22.7\%) who did not smoke had fair PFI grading, while 17 (34.0\%) who smoked had fair PFI grading. Poor grading was seen in 39 (26.0\%) who smoked in comparison to $30(60 \%)$ who did not smoke.

The association between PFI grading and presence or absence of smoking was seen using Chi-square test. $\mathrm{P}$ value obtained was $<0.05$, which is statistically significant, showing that there was a statistically significant difference in PFI grading between smoking and non-smoking subjects. 
Fig 02: PFI Grading According Smoking

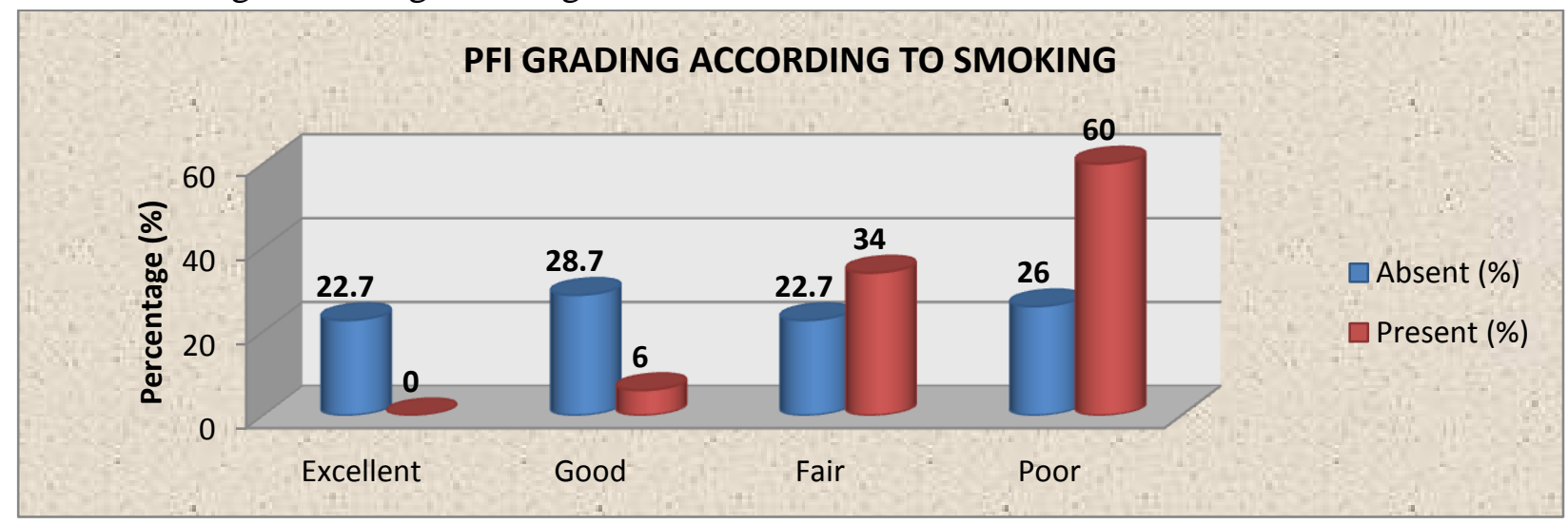

Table No. 3 Association of alcohol with PFI grading

$(\mathrm{N}=200)$

\begin{tabular}{|l|c|c|c|c|c|c|}
\hline \multirow{2}{*}{ PFI } & \multicolumn{2}{|c|}{ Absent } & \multicolumn{2}{c|}{ Present } & \multicolumn{2}{c|}{ Total } \\
\cline { 2 - 7 } Grading & No. & $\mathbf{\%}$ & No. & \% & No. & \% \\
\hline Excellent & 34 & 27.0 & 0 & 0.0 & 34 & 17.0 \\
\hline Good & 30 & 23.8 & 16 & 21.6 & 46 & 23.0 \\
\hline Fair & 24 & 19.0 & 27 & 36.5 & 51 & 25.5 \\
\hline Poor & 38 & 30.2 & 31 & 41.9 & 69 & 34.5 \\
\hline Total & 126 & 100.0 & 74 & 100.0 & 200 & 100.0 \\
\hline
\end{tabular}

Chi-square value $=27.48, \mathrm{df}=3, \mathrm{P}$ value $=0.0001$, Significant

The above table shows the association of PFI grading with presence or absence of alcohol consumption.

There were 34 (17.0\%) subjects who had excellent PFI grading, 46 (23\%) had good PFI grading, 51 $(25.5 \%)$ had fair PFI grading and $69(34.5 \%)$ had poor PFI grading.
$34(27.0 \%)$ subject who did not consume alcohol had excellent PFI grading, in comparison to none who consumed alcohol, while 30 (23.8\%) who did not consume alcohol had good PFI grading in comparison to 16 (21.6\%) subjects who consumed alcohol. 24 (19.0\%) subjects who did not consume alcohol had fair PFI grading in comparison to 27 $(36.5 \%)$ subjects who consumed alcohol. 38 $(30.2 \%)$ subjects had poor PFI grading who did not consume alcohol in comparison to 31 (41.9\%) subjects who consumed alcohol.

The chi-square test was applied to find out the association between PFI grading and presence / absence of alcohol consumption. $\mathrm{P}$ value obtained was $<0.05$, which is statistically significant, thereby showing that there is a strong association between the presence / absence of alcohol consumption to PFI grading.

Fig 03: PFI Grading According to Alcohol

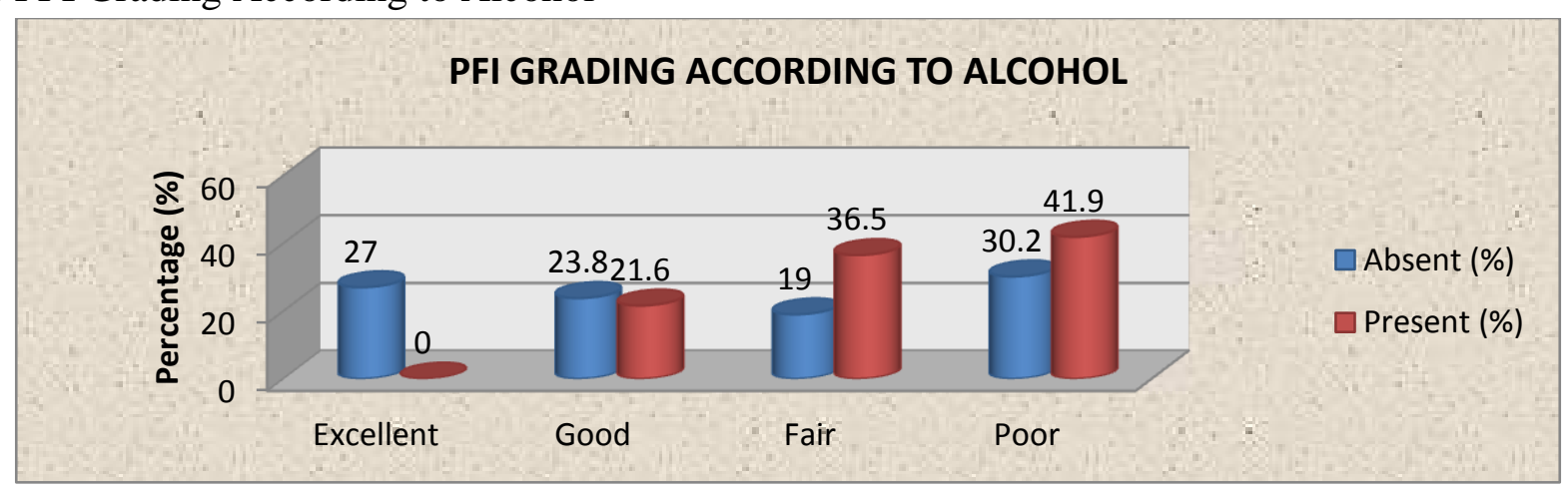

\section{Discussion}

The present study entitled "A Cross-sectional Study to Assess the Relation between Physical Fitness Index and Body Mass Index in Medical
Students of Index Medical College, Indore" evaluated the fitness of young medical students using Queen's College Step Test. This method has four grades of physical fitness based on scoring 
obtained after exercise.

200 medical students aged between 18 to 30 years were selected conveniently. This is one of the most suitable methods for assessing physical fitness of Indians as it does not require any special skill or equipment and is cost-effective also.

Other method with comparative simplicity is Harvard's Step Test but stepping cadence of HST is very high (17 inches) and it suits European and American Students better because they are tall, heavy statured, broad built.

For Indian setup, and our students Queen's College Step Test is most suitable because its height is 16.25 ".

Harvard's Step Test has been used several times but it was observed that premature fatigue of lower limbs rather than cardio-pulmonary exhaustion was altering the results. This problem was not noticed in Western students because their stature and knee length are higher than Eastern population.

Chatterjee et al (2005) ${ }^{[3]}$ used QCT to estimate $\mathrm{VO}_{2 \max }$ in female students.

Nabi et al (2015) ${ }^{[4]}$ used QCT for assessment of cardio-respiratory fitness in medicos (18-24 years) in Markandeshwar University, Ambala.

The present study showed that females had better physical fitness as compared to males, Majority of females $(36.6 \%)$ were in excellent and good groups as compared to males $(36.4 \%)$ in fair group and percentage of females in poor group was $17.1 \%$ as compared to males $(46.6 \%)$.

BMI differences in both genders was insignificant in excellent, good and fair groups, but had female predominance in poor group.

It was found that BMI was inversely proportional to physical fitness.

It was also observed that heart rate was inversely proportional to cardiorespiratory fitness.

Smokers had comparatively low physical fitness. Alcohol consumers showed variable response majority showed compromised fitness.

The present study is consistent with the study by Ganeriwal et al (1968) ${ }^{[5]}$ in which there was negative correlation between fitness index and body weight, pulse rate and positive correlation between fitness index and body height.

The present study agrees with the study by Mota et al $(2006)^{[6]}$ in which increased BMI was significantly associated with lower cardiorespiratory fitness in girls.

Pulse rate variability (pre and post exercise) was minimum among subjects who had excellent physical fitness and it was maximum among subjects who had poor physical fitness index.

The present study is also consistent with the study by Ted et al (1981), ${ }^{[7]}$ which revealed a decrease in resting heart rate and an increase in R-wave voltage in leads V5 and V6 and significant increase in resting $\mathrm{LV}$ end-diastolic dimension and volume following aerobic training program.

Systolic and diastolic blood pressure variabilities (pre and post exercise) were minimum in most of the subjects.

The present study is consistent with the study by Biswas et al (1996) ${ }^{[8]}$ reported that heart rate, systolic blood pressure, double product and respiratory rate rose linearly with increasing grades of exercise while diastolic blood pressure recorded a mixed response.

Physical fitness was correlated with BMI, physical activity, gender and cardiovascular variables. Physical fitness had a statistically significant negative correlation with BMI.

The present study agrees with the study by Rodrigues et al (2007), ${ }^{[9]}$ which reported that the faster heart rate was observed in the group with lower physical fitness (male and female). Additionally it is known that overweight and obese individuals exhibit lower levels of physical fitness.

In the present study subjects who had regular physical activity had better physical fitness and two variables were positively correlated.

In the present study females had better physical fitness as majority of them are pursuing physically active lifestyle though the study had established a strong positive correlation between physical fitness and female gender. It may be due to their involvement in some sort of physical activity. 
McArdle et al (1972) ${ }^{[10]}$ reported that variations in body mass may explain nearly $70 \%$ of the differences in VO2 max scores among individuals. This limits interpretation of exercise performance or absolute values for oxygen consumption when comparing individuals who differ in body size or composition in college women. The present study also showed that body mass influences physical fitness and indirectly oxygen consumption.

Pulse rate had a statistically significant negative correlation with the physical fitness in our study.

The present study agrees with the study by Elbel et al (1958), ${ }^{[11]}$ who reported the negative correlation between fitness index and initial pulse rate.

Pulse rate also had a negative correlation with the physical activity.

Systolic blood pressure and diastolic blood pressure had statistically significant positive correlation with physical fitness.

The present study is consistent with the study by Bhave et al (1989), ${ }^{[12]}$ who reported that blood pressure (SBP and DBP) increased during exercise stress testing along with pulse rate.

So, the present study concludes that physical fitness has linear relation with physical activity, height, abstinence from tobacco. It shows inverse relation with weight, BMI, alcohol and tobacco consumption and sedentary lifestyle.

\section{Conclusion}

Physical fitness of medical students in Index Medical College \& Hospital, Indore is not satisfactory. This may be due to their sedentary lifestyle, lack of sporting activities, overemphasis on academic pursuits and consumption of imbalanced diet and tobacco.

1. Females were in better state and physically more fit as they are calorie conscious and persued some sort of physical activity.

2. Regular physical activity is important determinant of physical fitness.

3. Over weight and obesity reduce physical fitness significantly.

\section{References}

1. Arthur C Guyton, John E Hall. Textbook of Medical Physiology. 12th ed. Noida (UP), India: Elsevier, Saunders; 2011. pp. 1038-9.

2. Claude Bouchard, Roy J Shephard, Thomas Stephens. Text book of physical activity, fitness, health. International Proceeding and Consensus Statement; 1994. pp. 286-8.

3. Chatterjee S, Chatterjee P, Bandyopadhyay A. Validity of Queen's College Step Test for estimation of maximum oxygen uptake in female students. Indian J Med Res 2005;121:32-5.

4. Nabi T, Rafiq N, Qayoom O. Assessment of cardiovascular fitness (VO2 max) among medical students by Queens College Step Test. International Journal of Biomedical and Advance Research IJBAR 2015;6(05):418-21.

5. Ganeriwal SK, Sen SC, Khandare SS. Test of physical fitness (Harvard Step Test) in Indian females. Indian $\mathbf{J}$ Med Res 1968;56:845-9.

6. Jorge Mota, Luana Flores, Luis Flores, Jose C Riberio, Maria P Santos. Relationship of single measure of cardiorespiratory fitness and obesity in young school children. Am J Hum Biol 2006;18:335-41.

7. Ted D Adoms, Frank G Yanowitz, Garth A Fisher, Douglas J Rides, Kreed Lovell, Allen T Pryor. Non-invasive evaluation of exercise training in college age men. Circulation 1981;64(5):958-64.

8. Dalia A Biswas, Jayant R Kher. Cardiorespiratory changes associated with graded exercise and determination of aerobic power in male medical students. Indian $\mathbf{J}$ Physiol and Pharmacol 1996;40(1):79-82.

9. Anabel N Rodrigues, Anselmo Jose Perez, Luciana Carlett, Nazare S Bissoli. The association between cardio-respiratory fitness and cardiovascular risk in 
adolescents. J Paediatria (Rioj) 2007;83(5):1-12.

10. McArdle WD. Reliability and interrelationships between maximal oxygen uptake, physical work capacity and step scores in college woman. Med Sci Sport 1972;4:182.

11. Elbel. Comparison of certain tests of physical fitness and certain bodily measurements. J Appl Physiol 1958;12:378.

12. Bhave $S$, Pherwani AV, Desai AG, Dattani KK. Cardio-respiratory response to stress test in normal Indian boys and adolescents. Indian Pediatrics 1989; 26:882-7. 